\title{
Exploring Behavioral Differences Between New and Repeat Cruisers to a Cruise Brand
}

\author{
Xiaodong Sun ${ }^{\mathrm{a}}$ \\ Robert Kwortnik ${ }^{\mathrm{c}}$ \\ Dinesh K. Gauri*b
}

November 8, 2017

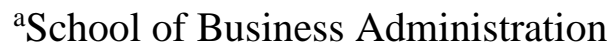

East China Normal University

Shanghai 200241, China

xdsun@bs.ecnu.edu.cn

bam Walton College of Business

University of Arkansas

Fayetteville, AR 72701, USA.

dkgauri@uark.edu

*correspondence author

\author{
'School of Hotel Administration \\ Cornell University \\ Ithaca, NY 14853, USA. \\ rkwortnik@cornell.edu
}

\section{Acknowledgements}

This study was supported by grants from the National Natural Science Foundation of China (No. 71572057), the National Natural Science Foundation of China (No. 71202134), the Shanghai Pujiang Program (No. 17PJC033) and the Tourism Young Expert Training Program of China National Tourism Administration (No. TYETP201522). 


\begin{abstract}
The modern leisure cruise industry is one of the most dynamic and profitable sectors of the global tourism industry. However, the cruise industry has entered a maturity stage in North America, the largest cruise market in the world, as growth of the new-to-cruise segment diminishes. Industry analysts emphasize that cruise lines need to not only attract new customers, but also to motivate existing ones to repurchase. Achieving these dual goals demands a better understanding of the differences between these market segments. This study used proprietary reservation data containing more than one million individual records of cruisers' demographic and behavioral information. Analysis showed that compared with new cruisers, repeat cruisers to a cruise brand are less price sensitive, live closer to embarking ports, are more likely to choose longer cruises and better cabin types, and to book cruises further out from the sailing date; in addition, there are notable behavioral differences between first-time and multi-time repeat cruisers.
\end{abstract}

Keywords: Cruise industry, Cruise loyalty, Behavioral segmentation 


\section{Exploring behavioral differences between new and repeat cruisers to a cruise brand}

\section{Introduction}

As one of the most dynamic and fastest-growing sectors of the global hospitality and tourism industries, the modern leisure cruise industry welcomed more than 24.2 million cruisers in 2016, with North America comprising 52.1\% of this passenger volume (CLIA, 2017). As the largest cruise market in the world, North America’s share of the global cruise market was more than 90\% before 2000, and more than 70\% from 2000 to 2011 (Sun et al., 2014). Researchers have identified a maturing phase in the North American cruise region (Jones, 2011), indicated by continued passenger growth, but a declining growth rate, decreasing global market share, and cruise lines moving ships to other regions, most notably Asia, to develop new markets where growth potential is stronger (Sun et al., 2014).

Despite this slowing growth in North America, only 20\% of this market has taken a cruise (CLIA, 2011; Sun et al., 2011) and only 3\% cruises each year (Rodrigue and Notteboom, 2013; Sun et al., 2014). While these figures should indicate potential for market development, industry leaders have raised concerns about the decline in new cruisers (Sampson, 2014), which comprised more than half the market in the early 2000s (Jainchill, 2006), down to 45\% by the middle of the decade (CLIA, 2008), and to 38\% in 2014 (CLIA, 2015). On the other hand, the growing repeater market (62\% of cruisers in 2014) presents opportunities for market penetration as cruise lines strive to encourage these customers who have taken 3.8 cruises on average (CLIA, 2015) to cruise more.

How cruise lines should allocate resources between market development and market penetration is both a strategic and analytic question; however, little empirical research exists in the cruise industry context to inform strategy (Petrick, 2005a). Academic research points to the 
benefits of repeat customers, including reduction of marketing and operational costs, generation of positive word of mouth (WOM), and growth of revenue streams (Oliver, 1980; Reichheld and Teal, 1996; Brunner et al., 2008). In tourism contexts, repeat patrons are important for destinations and suppliers (Fakeye and Crompton, 1992; Petrick and Backman, 2001; Petrick, 2004a; Chen and Chen, 2010). However, these benefits can be context dependent; in some industries and situations, loyal customers have higher expectations and actually cost more to serve than new customers, whereas some new customers who never rebuy can be highly profitable (Reinartz and Kumar, 2002).

The limited research on cruise loyalty has examined differences between new and repeat cruisers, though typically using self-report measures (e.g., Li and Petrick, 2008; Petrick, 2004b, 2005a; Jones, 2011). For example, Petrick (2004a), using self-report data from one cruise line sampled across two sailings, found few clear differences in terms of WOM, future intentions, price sensitivity, and money spent between new and repeat cruisers based on how often they had cruised with the brand. In follow-up analyses of this data, Petrick (2005a) found that new cruisers tended to be younger and that satisfied new cruisers and loyal repeaters had greater intentions to cruise again with the brand and to provide positive WOM (Petrick and Sirakaya, 2003). Jones (2011) studied self-reported influences on the decision to cruise by sampling from six cruises of one cruise line and found that new and repeat cruisers are influenced by different information sources, cruise attributes, and cruise motivations.

In terms of methodology, studies of new and repeat cruisers have largely used surveys and qualitative approaches, methods that may not reflect actual behavior. For instance, Petrick (2005b) reported that new and repeat cruisers do not differ in terms of self-identified price sensitivity, though actual cruise price paid and choice of cabin category may indicate otherwise. 
To the best of our knowledge, no research has used objective behavioral data to examine the differences between new and repeat cruisers. As such, this study offers a systematic, albeit exploratory, comparison of new and repeat-cruiser segments using actual bookings from a cruise line's proprietary reservations database consisting of more than a million records.

The study addresses limitations of past research, namely self-report and qualitative data collected from relatively small samples across at most a handful of cruises, by analyzing more than one million records of actual cruiser behaviors across hundreds of sailings and diverse itineraries for one cruise brand, making this study the first of its type in the travel and tourism literature. Results highlight a number of important differences between new and repeat cruisers to a brand that both clarify and extend past research, and that offer practitioners insights for behavioral segmentation for attracting new and retaining customers. The study's results also offer insights for revenue management based on segment differences in reservation timing, cabin-type selection, and prices paid. In sum, this research contributes to the literature by showing the value of using actual behavioral data for understanding segment differences, which offers implications for similar rigorous market analysis in other travel and tourism verticals. In the next section we review relevant literature on tourist segmentation and develop hypotheses based on past research. We then discuss this paper's methodology for reorganizing reservation records and identifying new and repeat cruisers, followed by the statistical methods used for examining differences between groups. We then present results obtained from a two-step framework about testing differences between new and repeat cruisers and then we discuss the results for sensitivity analysis for a three-group comparison that splits repeat cruisers into firsttime repeaters and multiple-time groups. We close with a discussion of the study's findings, 
implications for researchers and practitioners, and consideration of limitations and directions for future research.

\section{Literature review and hypothesis development}

Tourism researchers have identified a variety of differences between new and repeat customers in terms of demographic, psychographic, and behavioral factors, such as motivations (Fakeye and Crompton, 1992; Lau and McKercher, 2004; Lim et al., 2016), preferences and expenditure patterns (Lehto et al., 2004; Shani et al., 2012; Chang et al., 2013), satisfaction and loyalty (Chi, 2012; Morais and Lin, 2010), and perceived value and risk (Fuchs and Reichel, 2011; Karamustafa et al., 2013). However, cruises differ from other travel and hospitality products, making it challenging for consumers, especially novice buyers, to comprehend the cruise product during the choice process_-a main reason why travel agents still sell the majority of cruises (Mancini, 2011).

The cruise product is complex, consisting of itineraries of varied lengths and multiple ports of call, dozens of cabin categories, various onboard amenities and activities, numerous dining and entertainment venues, different kinds of shore excursions, and many spending opportunities, including alcohol and specialty dining, art auctions, gambling, and spa treatments; indeed, modern cruise ships are floating resorts—destinations unto themselves (Kwortnik, 2006). Given this complexity, we expect that cruisers with differing levels of product experience will also differ in terms of key buyer behaviors, such as when they will buy (reservation timing), how long of a cruise trip they will buy (trip duration), how far they will travel to a departure port (travel distance), and how much they will spend on their cruise vacation (cruise spending).

\subsection{Reservation timing}


In addition to the complexity of the cruise product, cruising has long suffered from a variety of real or perceived objections to the experience that are especially prevalent among noncruisers, such as high cost of cruising, worries about seasickness or ship safety, concerns about being confined on the ship, beliefs about regimentation and forced socialization, and a general lack of knowledge about cruising (Mancini 2011). Such objections exacerbate decision uncertainty. Travel risk has been identified as a major concern for tourists when planning a vacation (Lo et al., 2011; Reisinger and Mavondo 2005), particularly when knowledge about the tourism product is low (Wong and Yeh, 2009). Travelproduct information is important for reducing purchase uncertainty (Gursoy and McCleary, 2004). Lo et al. (2011) showed that search for the latest information about a destination was a primary method that tourists adopted to reduce purchase risk. Furthermore, in the trip-planning phase, perceived risk can result in tourists delaying their final decision (Wong and Yeh, 2009). Accordingly, compared to repeat cruisers with more knowledge about cruising and fewer objections based on prior experience, new cruisers face a higher level of uncertainty and will require more time to obtain relevant product information before reserving their cruise. Thus, it is hypothesized that:

H1. New cruisers will book their cruises later (i.e., closer to the trip) than repeat cruisers.

\subsection{Trip duration}

In terms of travelers' length-of-stay choices, previous research offers mixed findings. Oppermann $(1997,1998)$ reported that compared to new visitors, repeat visitors to New Zealand stayed longer in the country. Similarly, Tiefenbacher et al. (2000) found that repeat visitors to small towns in Texas stayed in the location longer than did new visitors. Wang (2004) likewise found that repeat tourists from mainland China to Hong Kong were more likely to stay longer than new visitors (see also Lau and McKercher 2004). However, Li et al. (2008) reported the 
opposite- that new visitors were more likely to stay longer than repeaters (see also Shani et al. (2012)). In the cruise industry, CLIA (2011) reported that novice cruisers generally allocate less time for their first cruise than for subsequent cruises in order to "test" the cruise vacation experience; thus, it is proposed that:

H2. New cruisers will purchase shorter cruises than repeat cruisers.

\subsection{Travel distance}

In tourism geography, research on the impact of distance on tourist behavior generally finds that demand declines with distance to the destination (McKercher, 2008). In the cruise context, the need to travel further to reach departure ports would also increase the overall trip cost and associated purchase risk. However, research shows that new visitors to a destination tend to travel greater distances than do repeat visitors (Tiefenbacher et al., 2000). Li et al. (2008) noted that repeat visitors were more likely to drive to their destinations, whereas new visitors tended to travel further distances by flying. Along these lines, it is proposed that new cruisers are more likely to live farther away from departure ports, and repeat cruisers are more likely to live closer.

H3. New cruisers will travel farther to reach embarking ports than will repeat cruisers.

\subsection{Cruise spending}

Tourism researchers have argued that repeat visitors form an important market for destination management (Fakeye and Crompton, 1992; Petrick and Backman, 2001; Petrick, 2004a; Chen and Chen, 2010). Conventional wisdom in the cruise industry holds that repeaters tend to choose more expensive cruise brands (FCCA, 2012) and to spend more on their cruises (Applegate et al., 2006). However, as Petrick (2004a) stated, “it is only an assumption...that repeat visitors are good visitors.” In contrast, Oppermann (1997) showed that new tourists to 
New Zealand tended to spend more money than repeaters. Likewise, Petrick (2004a) reported that new cruisers tended to spend more on their trips. Despite the conflicting findings in the tourism literature (Shani et al., 2012), we expect that new cruisers will pay less for their trips and will book lower-priced cabin categories (suites and balcony cabins vs. ocean view and interior cabins) than repeat cruisers, consistent with conventional wisdom in the industry and the prediction in this paper that new cruisers will book shorter trips. Thus, it is hypothesized that:

H4. New cruisers will pay less for their cruise tickets than repeat cruisers.

H5. New cruisers will choose less expensive cabins than repeat cruisers.

Fig. 1 summarizes the empirical framework examined in the study that follows.

\section{Methodology}

The data for this research was obtained from the reservation system of a major cruise line based in North America that serves the mass market, and features more than a million passenger records across 2 years. Each record includes booking information as well as demographics for an individual cruiser (gender, age, city, state, and country). Booking information includes cruise identifier (a unique code given to each cruise), itinerary, embarkation port (4 ports in Florida, $\mathrm{USA}^{1}$ ), date of sailing, duration of the cruise (2-16 days), booking date, cabin type selected, and price paid. To examine travel distance, it was necessary to obtain the distance between cruisers' locations and the embarkation ports in Florida. Although the data included the city and state of residence of the cruiser, to simplify analysis across more than one million records, the distance between the capital of the home state and Orlando (centrally located in Florida) was used as each cruiser's distance information. Cruisers sourced from Florida were assigned one hundred miles

\footnotetext{
${ }^{1}$ We call these Port 1 , Port 2, Port 3 and Port 4 to maintain confidentiality of the data.
} 
as the distance to the departure port given that the most populous areas of Florida are within 100 miles of one of the four state cruise ports. The reservation database did not contain information about past cruise experience. Based on the assumption that a cruiser used the same phone number to book his/her cruise vacation across the two-year booking window, the same phone number identifier across different booking records represented repeat cruisers.

The focus on customer behavior associated with one cruise brand, combined with the relatively narrow booking window for an infrequently purchased tourism product, constrained the data in such a way that distinctions between new and repeat cruisers would be more evident — but this also limited the set of repeat cruisers to the brand. To obtain independent samples, all new-cruiser data and only the most recent records for repeat cruisers was retained. For example, for five-time cruisers, only used the fifth record for the five-time-cruiser sample was used. This data qualification process yielded 1,061,384 records, with 1,020,530 new cruisers, 36,466 two-time cruisers, 3454 three-time cruisers, 634 four-time cruisers, 186 fivetime cruisers, and 114 cruisers with more than five cruises with the company during the two-year data period, accounting for $96.15 \%, 3.44 \%, 0.33 \%, 0.06 \%, 0.02 \%$ and $0.01 \%$, of the total sample respectively. Finally, selecting only those cruisers who identified as U.S. residents yielded a final sample of 1,026,689 booking records. Because of limited records for cruisers with more than five cruises with the company, only those records spanning from new to five-time cruisers was used for analysis. Furthermore, because of the large number of records for the new cruiser segment, $10 \%$ of the records for this group was randomly selected as the sample for analysis. Table 1 shows the final sample for analysis.

A two-stage procedure was employed to analyze differences between the new and repeat cruisers. In the first stage, differences in choice behavior was tested using binary comparison, 
independent t-test analysis for continuous variables including location, cruise duration, price paid, and reservation timing, and chi-square analysis for categorical variables (e.g., cabin type). In the second phase, sensitivity analysis was used to compare new, first-time repeat and multitime repeat cruiser groups. The three-group scenario used one-way ANOVA and chi-square analysis with a multiple comparison procedure for continuous variables and categorical variables, respectively.

\section{Results}

Table 2 shows demographic and booking behavior for the study sample. In terms of gender, $54.1 \%$ of the sample is female and $45.3 \%$ are male. The cruisers' average age is 44.29 , with means of 42.11 and 45.96 for new and repeat cruisers, respectively; this age difference is significant $(t=-77.11 ; \mathrm{p}<0.001)$. One-way ANOVA also revealed significant differences $(F=3210.13 ; \mathrm{p}<0.001)$ in age between the three groups. Post-hoc analysis with Tukey's HSD test showed that multi-time cruisers are significantly older (mean=54.27 years) than first-time repeat cruisers to the brand (mean=48.99 years) and new cruisers (mean=42.11 years), and firsttime repeat cruisers are significantly older than new cruisers, consistent with prior research showing that new cruisers are younger than repeat cruisers (Petrick 2005a).

\subsection{Reservation timing (H1)}

In the cruise industry, there tends to be a long booking window, often months in advance of the sailing date. With respect to cruisers' reservation timing before sailing, new cruisers booked their trips closer to the sailing date (an average of 12.57 week prior) than repeat cruisers to the brand (an average of 13.18 weeks prior) $(t=-8.68 ; \mathrm{p}<0.001)$; see Table 3a for the results of binary comparison. Multi-group analysis using one-way ANOVA also showed significant 
differences between the three behavioral groups ( $F=56.21$; $\mathrm{p}<0.001)$; see Table $3 \mathrm{~b}$ for the results of multi-group comparison. However, post hoc analysis revealed a more complicated pattern: the brand's multi-time cruisers actually booked closer in (mean 12.19 weeks out) than did new cruisers (mean 12.57 weeks out), though first time repeat cruisers booked the farthest out (mean=13.30 weeks out). Therefore, $\mathrm{H} 1$ is rejected.

\subsection{Cruise duration (H2)}

In terms of cruise length, the average duration was 5.60 days, with a mean of 5.46 days for new cruisers and 5.94 days for repeat cruisers to the brand. The independent-sample t-test indicated that this difference is significant $(t=-42.73 ; \mathrm{p}<0.001)$. Multi-group analysis using one-way ANOVA yielded significant differences between cruiser groups ( $\mathrm{F}=960.92 ; \mathrm{p}<0.001)$. However, post-hoc analysis with the Games-Howell test showed that cruise duration of the brand's first-time repeat cruisers (mean=5.93 days) and multiple-time repeat cruisers (mean=5.97 days) was not statistically different. In general, these results support hypothesis H2 and are consistent with industry research suggesting that new cruisers test the cruise vacation experience by allocating less time for their first cruise than to subsequent cruises (CLIA, 2011).

\subsection{Travel distance (H3)}

The data showed that average travel distance to embarking ports was 690.98 miles. An independent sample t-test revealed that repeat cruisers to the brand were more likely to live closer to departing ports than new cruisers, with mean distance to Orlando (Florida) of 546.79 miles and 750.63 miles, respectively $(t=60.90 ; \mathrm{p}<0.001)$. One-way ANOVA showed significant differences ( $F=2008.33$; $<$ 0.001) between behavioral groups. Because of unequal variances (Levene's test $F=35.48, \mathrm{p}<0.001$ ) and unequal sample sizes, post hoc analysis with the GamesHowell test was used for multiple comparisons. Results showed that new cruisers traveled 
significantly farther to embarkation ports (mean=750.63 miles) than both the brand's first-time repeat (mean=563.68 miles) and multi-time repeat cruisers (mean=406.97 miles), in support of H3.

\subsection{Cruise spending (H4)}

The brand's cruisers spent an average of $\$ 461.80$ on their cruise fare, with new cruisers spending \$451.77 and repeaters spending \$486.03. Results of the independent-sample t-test showed significant differences between cruiser groups, though in the opposite predicted direction $(\mathrm{t}=-19.86 ; \mathrm{p}<0.001)$. Unlike previous research (Kalyanaram and Little, 1994; Oppermann, 1997; Petrick, 2004b), though consistent with conventional wisdom in the cruise industry, we found that new cruisers are more price sensitive than repeaters, spending less on their trip. Results of the multi-group ANOVA also revealed significant differences between groups ( $F=210.27 ; \mathrm{p}<0.001)$. Post hoc analysis with Tukey's HSD showed that new cruisers spent less (\$451.77) than both the brand's first-time repeat (mean=\$487.20) and multi-time repeat cruisers (mean=\$476.38). It is notable that we found a concave pattern in terms of price and cruise history, indicating that multi-time repeat cruisers to the brand paid significantly less ( $\mathrm{p}<0.05$ ) than cruisers repeating for only the first time, though both groups paid significantly more than new cruisers. Therefore, $\mathrm{H} 4$ is supported.

\subsection{Cabin selection (H5)}

With respect to cabin-type selection, more than $75 \%$ of the brand's cruisers selected interior (39.8\%) and ocean view (38.7\%) cabins, followed by balcony cabins (17.0\%) and suites (4.5\%). We found significant differences between segments $\left(x_{(3)}^{2}=1401.98 ; \mathrm{p}<0.001\right)$, indicating that new cruisers were more likely to book what are typically lower-cost cabin categories than repeat cruisers to the brand: interior cabins (new cruisers (40.2\%) vs. repeaters 
(38.8\%)) and ocean-view cabins (new cruisers (40.8\%) vs. repeaters (33.5\%)). In contrast, new cruisers were less likely to book better cabin categories: balcony cabins (new cruisers (14.4\%) vs. repeaters (23.2\%)), though, interestingly, new and repeat cruisers to the brand were equally likely to book suites (4.5\% each).

Multi-group chi-square analysis of cruisers’ cabin-type selection reveals significant differences between the three groups $\left(x_{(3)}^{2}=1438.52\right.$; $\left.\mathrm{p}<0.001\right)$. Multi-time repeat cruisers to the brand were more likely to choose better cabin types—suites (5.1\%) and balcony cabins (25.9\%) than first-time repeaters (4.5\%, and $23.0 \%$ respectively) and new cruisers $(4.5 \%$, and $14.4 \%$ respectively). Multi-time repeat cruisers were less likely to choose ocean-view cabins (28.9\%) than first-time repeaters (34.1\%) and new cruisers (40.8\%). However, the choice pattern was less clear for interior cabins, with multi-time repeaters choosing this category in similar proportion to new cruisers (40.1\% vs. 40.2\%), but significantly more than first-time repeaters (38.5\%). In general, the findings indicated that repeaters, in particular multi-time repeat cruisers, were more likely to choose better cabins than consumers taking their first cruise. Thus, H5 is supported.

Cruise fares are usually associated with cabin types, though there can be considerable variability in prices paid within category. Given this we re-examined hypotheses 4 and 5 by testing for between-subjects effects of the relationship between cruiser behavioral group, cabin type, and their interaction (cruiser group * cabin type) on price, starting first with the binary comparison of new cruisers to the brand and repeaters. As Table 4 shows, analysis produced statistically significant interaction and main effects $(\mathrm{p}<0.001)$. Therefore, we further explored the mean difference in price between groups in each cabin type.

As shown in Table 5, for balcony, ocean view, and suite cabins, significant differences (p $<0.001$ ) between new and repeat cruisers are found in terms of price paid, but not for the interior 
category ( $p>0.05)$. The pattern of results for price paid within category by new cruisers and repeaters is complex. For higher-end suite cabins, the choice proportion is the same for each group (4.1\%), but new cruisers paid significantly less (\$919.25) than repeat cruisers to the brand (\$991.52). On the other hand, repeat cruisers were more likely to choose a balcony cabin (20.9\%), but paid less (\$763.60) than new cruisers (13.1\% and \$788.81). Finally, new cruisers were more likely to stay in an ocean-view cabin (37.0\%) and to spend less on it (\$413.36) than were repeat cruisers (30.3\% and \$436.02).

To shed additional light on the price and cabin-type analysis, we used correspondence analysis, a statistical technique for representing the rows and columns of a two-way contingency table, to show the frequency of selection of cabin types across the three cruiser segments. The joint plot reveals the interrelationships between cruiser segments and cabin types, where the closer the categories are, the more they are associated. As Fig. 2 demonstrates, new cruisers tended to choose ocean view and interior cabins, whereas repeat cruisers to the brand were more likely to select balcony and suite cabins. This finding further supports the price-sensitivity results by showing that repeat vacationers were more likely to pay more for a better cabin.

Multi-group one-way ANOVA of price paid within cabin category revealed differences for all four categories: suite $(F=19250.35$; $\mathrm{p}<0.001)$, balcony $(F=29.11$; $\mathrm{p}<0.001)$, ocean view ( $F=18.33 ; \mathrm{p}<0.001)$, and interior $(F=4.63 ; \mathrm{p}<0.05)$ between the three cruiser segments (see Table 6 and Fig. 3), though the pattern of differences varies. Post-hoc analysis with Tukey’s HSD test indicated significant differences in prices for some, but not all groups within cabin type. For suites, multi-time repeat cruisers paid less (\$981.08) than first-time repeat cruisers (\$992.92), but not than new cruisers (\$919.35). For balcony cabins, multi-time repeat cruisers spent less (\$742.52) than both first-time repeat cruisers (\$766.31) and new cruisers (\$788.81). 
For ocean-view cabins, multi-time cruisers spent significantly more (\$428.94) than new cruisers (\$413.36), but less than first-time repeat cruisers (\$436.74), though the results for the latter comparison were not statistically significant. Finally, for interior cabins, multi-time repeat cruisers spent significantly less (\$345.21) than first-time repeat cruisers (\$358.37) and new cruisers (\$354.38), though the latter difference was not statistically significant. In general, although the results across cabin types were mixed, the pattern for price paid within cabin category indicates that multi-time cruisers paid less for their cabins than first-time repeaters, who also generally paid more than new cruisers; however, the pattern is split between multi-time repeaters and new cruisers. These results suggest first-time repeat cruisers to the brand were willing to pay more for a better experience, but that as cruisers gained product knowledge through repeat purchases, they became more price sensitive, a finding consistent with prior research (e.g., Kalyanaram and Little, 1994; Oppermann, 1997; Petrick, 2004a).

\section{Discussion and implications}

Using a two-stage analytic approach, this study uncovered a set of differences between new and repeat cruisers to a cruise brand in terms of six important consumer behaviors: 1) reservation timing; 2) trip duration; 3) travel distance to the cruise port; 4) price paid for the cruise fare; 5) cabin-type selection; and, 6) price paid for each cabin type. A summary of results, compared with previous studies is presented in Table 7. In general, the results show that compared with repeat cruisers, new cruisers booked their cruises closer to the departure date, were more price sensitive, traveled farther to embarking ports, were more likely to choose shorter cruises, and were more likely to purchase less expensive cabin types. However, a few of these findings are qualified when we examine cruisers who are repeating for the first time vs. 
those repeating for multiple times. Specifically, we found that cruisers taking their third or more cruise with the brand tended to be older, were more price sensitive, lived closer to embarking ports, were more likely to choose longer cruises and better cabin types, and booked closer to the departure date than cruisers repeating for only the first time. The clear implication of these findings is that not all brand repeaters are alike and that the multiple-repeat segment may be more demanding than the first-time repeater. Thus, the generally accepted notion that repeat cruisers are more profitable is suspect given the empirical results from this study. The behavioral segment that appears to be most attractive are the first-time repeaters to the brand who are willing to invest more in their second cruise, but who have not yet developed the product knowledge and price sensitivity of multi-time repeat cruisers to the brand.

\subsection{Implications for marketing management}

Consistent with previous studies in tourism (e.g., Gitelson and Crompton, 1984;

Tiefenbacher et al., 2000; Lau and McKercher, 2004; Li et al., 2008), the current research shows that new cruisers are younger than repeaters. Accordingly, to attract new cruisers, cruise lines should target younger consumers with media and messages that will best connect with a younger demographic. According to Cruise Lines International Association, from 2002 to 2013, only 6\%8\% of cruisers per year were between the ages of 25 and 29 (CLIA, 2008 2011, 2015). To be more successful in attracting younger cruisers, the industry needs to dispel notions that a cruise ship is confining, with a strict daily schedule for dining, limited entertainment and activity options, and not enough time to spend at destinations. Arguably, the industry should leverage the story-telling platform facilitated by social media and digital broadband (video) to present a vibrant, diverse, and novel vacation experience ideally suited to younger travelers. 
Furthermore, younger consumers likely have less vacation time and budget than older travelers, which is why we find that new cruisers are younger and more likely to choose shorter cruises and generally spend less than repeaters. Therefore, to attract younger cruisers, cruise lines should promote shorter (e.g., less than one week or long-weekend) itineraries and value-formoney cruises to the millennial market while highlighting the many social activities, diverse facilities, and forms of entertainment available onboard. Cruise lines targeting new cruisers might also feature the getaway benefits of embarkation ports and/or discounted air/sea packages, given that new cruisers are more likely to travel greater distances to take a cruise.

The marketing effort for repeat cruisers also should be tailored to this segment—and to the behavioral differences within this market. Our results show that repeaters to the brand tend to come from source markets closer to departure ports, that the booking window is longer, and that they are less price sensitive. These three factors indicate opportunities for targeting nearby markets of repeaters (i.e., accessible through travel agent partners or a cruise line’s own database) with upsell message or value-add offers—especially for first-time repeaters to the brand, the second-time cruisers. Multi-time repeaters require a different approach, as they book closer in and are generally more price sensitive, giving the impression of a more knowledgeable, savvier cruise shopper. These repeaters may be more attracted to discount offers closer to the date of sailing.

In terms of lodging preferences, the results of this research further indicate that differences exist between behavioral groups in their choice of cabins. Specifically, the findings reveal that new cruisers tend to sample the cruise experience by choosing less costly interior and ocean-view cabin types, while repeaters to the brand are more likely to upgrade by selecting balcony cabins (and for multi-time repeaters, by selecting suites). These findings make both 
intuitive and theoretical sense-repeaters who enjoyed their first value-oriented cruise experience might aspire to a richer hedonic experience by traveling in a cabin featuring a balcony overlooking the sea, even if this is a more costly option (Kwortnik and Ross, 2007; Miao et al., 2014). Therefore, in the pre-purchase, dreaming phase of the cruise decision process, cruise marketers could highlight the enhanced pleasure and experience benefits of the balcony and suite cabins when messaging to repeat customers, as well as appeal to the repeater's sense of product expertise as cruise veterans who know the value of enhanced onboard lodging.

Finally, it is generally accepted that cruise lines need to carefully manage the sales horizon to sail at full capacity and optimize both the ticket price and onboard revenue. Typically, the earlier that customers book their cruise, the more the cruise line is able to maximize yield. Consistent with previous research on general tourist behavior (e.g., Li et al., 2008), our results showed that repeat cruisers to the brand-more so the first-time repeat cruisers—are more likely to book earlier (further out) than are new cruisers. This finding can be explained by the uncertainty novice cruisers face in the cruise decision process, as well as greater constraints they have on available travel time. Gathering decision information is important for travelers to reduce uncertainty or risk (Gursoy and McCleary, 2004; Lo et al., 2011) and to decrease related information search efforts/costs; the closer-in booking behavior of novice cruisers is consistent with the greater information-search behavior of general tourists. To stimulate early reservations from new cruisers, cruise marketers need to simplify the information requirements and decision process. As a first step, it is important to understand the information sources and needs that new cruisers will rely on for their decision (Chen and Gursoy, 2000; Baloglu, 2001).

\subsection{Implications for revenue management}


Like airlines and hotels, cruise lines face the challenge of selling the right products to the right consumers at the right prices at the right time through the right channels with the purpose of maximizing total revenue (Kimes, 1989; Sun et al., 2011). Given the nature of the cruise industry, with segmented markets, fixed capacity, perishable inventory, a finite booking window, and advanced sales (Sun et al., 2011), revenue management is a vital tool for effective capacity control and dynamic pricing strategies. However, because the cruise industry serves discretionary leisure travelers (Toh et al., 2005), there are particular difficulties associated with segmenting customers and a longer booking window that make revenue management challenging. The more that revenue managers know about the differences between market segments (e.g., between behavioral segments), the better they can mitigate these challenges.

One objective of segmenting markets is to differentiate between consumers with differing price sensitivity and willingness to trade-off price for purchase timing and varying service levels (Sun et al., 2011). The data used in this study features elements that are important to revenue management, such as multiple cabin types, different prices, and varied reservation timeframes before departure. As such, the current study sheds light on how to behaviorally segment cruisers for revenue management. Our results reveal differences between new cruisers and repeaters to the brand in terms of cabin-type selection, price paid, and booking time. Thus, according to Phillips (2005) and Sun et al. (2011), from a pricing and revenue optimization (PRO) perspective, segmenting customers based on past experience can produce a revenue management optimization problem (see Fig. 4), where pricing control is a powerful tool for incorporating other factors.

According to results of this research, there are significant differences in pre-departure booking windows, willingness to pay, and cabin-type preference between new cruisers and 
repeaters to the brand. It is notable that we found that new cruisers usually booked later than repeaters across cabin types. Generally, balcony and suite cabins were reserved earlier than interior and ocean-view cabins. Combining these findings, our results suggest that new cruisers generally book later and prefer to spend less on interior and ocean view cabins, while repeaters to the brand tend to book further out and prefer balcony and suite cabin even though they tend to spend more on this cabin category. These findings are useful for revenue managers, as they use the pricing lever to fill cabins of different categories across behavioral segments. For example, based on booking data, weeks left to sail, the number of cabins still available, and fare classes offered, cruise managers could determine what price promotions to launch, continue, or stopand for which behavioral segment—when product availability increases or decreases for the most responsive segment.

The results of this study further suggest that price differentiation such as channel pricing and regional pricing can be a powerful means for cruise lines to improve efficiency and profitability. For example, with the appropriate rate fences in place (e.g., prices across cabin categories), pricing could be different in the travel-agent vs. online channel depending upon which behavioral segment and location markets these channels serve most effectively. Likewise, regional pricing could be achieved by offering price flexibility depending on customers' distance to cruise ports and past cruise experience. In general, our results show that repeat cruisers to the brand - especially first-time repeaters - are more desirable than new cruisers, because they are more likely to reserve earlier and to spend more on most cabin types. When demand is high, increasing revenue per guest by optimizing product availability and price is critical. The goal is to avoid buy-down behavior of less price sensitive segments (e.g., first-time repeaters) to better ensure that they will purchase higher-priced cabins; this is the type of behavior that our data 
indicate is common with multi-time repeat cruisers. To avoid buy-down behavior, interior and ocean view cabins could be closed earlier for new cruisers, because they usually book later and spend less than repeaters. In contrast, protection level of balcony cabins for new cruisers could be adjusted to a higher threshold, and upgrading from an interior and ocean-view cabin to balcony cabin with a higher price may be accepted by new cruisers.

When demand is low, stimulating early booking is important. In addition to offering early booking incentives, such as a price guarantee, a discounted or value-added vacation package (e.g., air-sea) could be offered to remote new cruisers to expand the customer pool as well as to improve profit per guest. For repeaters to the brand, as the departure time nears, markdown pricing for particular cabin types could also be effective for stimulating demand. In terms of capacity allocation, interior and ocean view cabins with discounted fare classes could be closed later for new cruisers than usual. For balcony cabins, a protection level could be set to a high threshold to satisfy repeaters, although the multiple repeaters to the brand generally spend less than new cruisers. For effective RM practice, demand forecasting for each segment and theoretical revenue management models for optimal capacity control and dynamic pricing deserve more attention in future research.

\section{Conclusions and limitations}

Although the global cruise industry is still in the growth stage, the North American market has matured, making it increasingly important to better manage market demand by attracting new customers and inducing existing ones to repurchase. Toward these dual goals, cruise marketers should look to behavioral segmentation based on past customer experience and to identify differences between new cruisers and repeaters. Previous studies in the general 
tourism context have revealed a variety of differences between new visitors and repeaters; however, few studies have looked into the cruise market. This study contributes to the literature by providing a systematic and comprehensive comparison of behavioral segments in the cruise industry to understand segment differences in term of both booking behavior and demographics. Unlike most previous research that uses subjective surveys to collect data, this study used a database containing objective booking records. Based on the findings from the study, we provide the industry with relevant managerial implications for brand management for attracting new customers and repeat customers, as well as for enhancing sales from a revenue management perspective.

Although these data and analyses yield statistically and practically significant findings, we faced several limitations that affect the generalizability of the results. First, this study is limited by the two-year booking window for one cruise brand. There is the possibility that some cruisers categorized in the new-cruiser category have cruised earlier with the brand than the dataset might indicate; or it is possible that the phone number used to identify the repeat cruisers may not indicate the same persons. For instance, different family members may use the same phone number for different cruises, or the same cruisers may have used different phone numbers to book a repeat cruise.

Additionally, the data does not indicate if members of the sample cruised with other cruise companies. Although a large number of records are used in this study, we were limited to data from one company for analysis. The database also does not contain information about onboard spending or shore excursion activities that could be different between behavioral segments. To enrich the insights and generalizability of this research, it would be useful to obtain a more complete picture of the behaviors of cruisers, from their booking activity to their onboard 
and post-cruise activity, both within and across cruise brands. Fortunately, cruise lines have grasped the benefits of robust data management systems and the intelligence these systems can yield; therefore, it is for future research to tap into this data to further explore the differences between new and repeat-cruise customers for a brand and for cruise vacations across brands. 


\section{References}

Applegate, L., Kwortnik, R.J., Piccoli, G., 2006. Carnival cruise lines. Harvard Business School Case Series. (9-806-015), April 24, 2006.

Baloglu, S., 2001. Image variations of Turkey by familiarity index: informational and experiential dimensions. Tour. Manage. 22 (2), 127-133.

Brunner, T.A., Stocklin, M., Opwis, K., 2008. Satisfaction, image and loyalty: new versus experienced customers. Eur. J. Mark. 42 (9/10), 1095-1105.

Cruise Lines International Association (CLIA), 2008. Cruise Market Profile Study. http://www.cruising.org.

Cruise Lines International Association (CLIA), 2011. Cruise Market Profile Study. http://www.cruising.org/docs/default-source/market-research/2011-market-profile-study. pdf?sfvrsn=0, (Accessed 15 January 2016).

Cruise Lines International Association (CLIA), 2014. 2014 North American Cruise Market Profile. http://www.cruising.org/docs/defaultsource/research/clia_naconsumerprofile_2014.pdf, (Accessed 15 January 2016).

Cruise Lines International Association (CLIA), 2017. CLIA 2017 State of the Industry Report. . http://www.cruising.org/about-the-industry/research/2017-state-of-theindustry, (Accessed 31 May 2017).

Chang, K.L., Chen, C.M., Meyer, T.J., 2013. A comparison study of travel expenditure and consumption choices between first-time and repeat visitors. Tour. Manage. 35, 275-277.

Chen, C., Chen, F., 2010. Experience quality, perceived value, satisfaction and behavioral intentions for heritage tourists. Tour. Manage. 31 (1), 29-35. 
Chen, J.S., Gursoy, D., 2000. Cross-cultural comparison of the information sources used by firsttime and repeat travelers and its marketing implications. Int. J. Hosp. Manage. 19 (2), 191-203.

Chi, C.G.Q., 2012. An examination of destination loyalty: differences between first-time and repeat visitors. J. Hosp. Tour. Res. 31 (1), 3-24.

Florida-Caribbean Cruise Association (FCCA), 2012. Cruise Industry Overview_2012. http://www.f-cca.com/downloads/2012-Cruise-Industry-Overview-Statistics.pdf, (Accessed 18 July 2016).

Fakeye, P.C., Crompton, J.L., 1992. Importance of socialization to repeat visitation. Ann. Tour. Res. 19 (2), 364-367.

Fuchs, G., Reichel, A., 2011. An exploratory inquiry into destination risk perceptions and risk reduction strategies of first time vs. repeat visitors to a highly volatile destination. Tour. Manage. 32 (2), 266-276.

Gitelson, R.J., Crompton, J.L., 1984. Insights into the repeat vacation phenomenon. Ann. Tour. Res. 11 (2), 199-217.

Gursoy, D., McCleary, K.W., 2004. An integrative model of tourists’ information search behavior. Ann. Tour. Res. 31 (2), 353-373.

Jainchill, J., 2006. Steep decline in first-time cruisers concerns Dickinson. Travel Weekly. November 6, 2006.

Jones, R.V., 2011. Motivations to cruise: an itinerary and cruise experience study. J. Hosp. Tour. Manage. 18 (1), 30-40.

Kalyanaram, G., Little, J.D., 1994. An empirical analysis of latitude of price acceptance in consumer package goods. J. Consum. Res. 21, 408-418. 
Karamustafa, K., Fuchs, G., Reichel, A., 2013. Risk perceptions of a mixed-image destination: the case of Turkey’s first-time versus repeat leisure visitors. J. Hosp. Mark. Manage. 22 (3), 243-268.

Kimes, S.E., 1989. Yield management: a tool for capacity-considered service firms. J. Oper. Manage. 8, 348-363.

Kwortnik, R.J., Ross, W.T., 2007. The role of positive emotions in experiential decisions. Int. J. Res. Mark. 24 (December), 324-335.

Kwortnik, R.J., 2006. Carnival cruise lines: burnishing the brand. Cornell Hotel Restaur. Adm. Q. 74 (3), 286-300.

Lau, A.L., McKercher, B., 2004. Exploration versus acquisition: a comparison of first-time and repeat visitors. J. Travel Res. 42 (3), 279-285.

Lehto, X.Y., O’Leary, J.T., Morrison, A.M., 2004. The effect of prior experience on vacation behavior. Ann. Tourism Res. 31 (4), 801-818.

Li, X.R., Petrick, J.F., 2008. Examining the antecedents of brand loyalty from an investment model perspective. J. Travel Res. 47 (1), 25-34.

Li, X.R., Cheng, C.K., Kim, H., Petrick, J.F., 2008. A systematic comparison of first-time and repeat visitors via a two-phase online survey. Tour. Manage. 29 (2), 278-293.

Lim, Y.J., Kim, H.K., Lee, T.J., 2016. Visitor motivational factors and level of satisfaction in wellness tourism: comparison between first-time visitors and repeat visitors. Asia Pac. J. Tour. Res. 21 (1), 137-156.

Lo, A.S., Cheung, C., Law, R., 2011. Hong Kong residents’ adoption of risk reduction strategies in leisure travel. J. Travel Tour. Mark. 28 (3), 240-260. 
Mancini, M., 2011. The CLIA Guide to the Cruise Industry. Delmar, Cengage Learning, Clifton Park, NY.

McKercher, B., 2008. The implicit effect of distance on tourist behavior: a comparison of short and long haul pleasure tourists to Hong Kong. J. Travel Tour. Mark. 25 (3-4) 367-381.

Miao, L., Lehto, X., Wei, W., 2014. The hedonic value of hospitality consumption: evidence from spring break experiences. J. Hosp. Mark. Manage. 23 (2), 99-121.

Morais, D.B., Lin, C.H., 2010. Why do first-time and repeat visitors patronize a destination? J. Travel Tour. Mark. 27 (2), 193-210.

Oliver, R.L., 1980. A cognitive model of the antecedents and consequences of satisfaction decisions. J. Mark. Res. 17, 460-469.

Oppermann, M., 1997. First-time and repeat visitors to New Zealand. Tour. Manage. 18 (3), $177-181$.

Oppermann, M., 1998. Destination threshold potential and the law of repeat visitation. J. Travel Res. 37 (2), 131-137.

Petrick, J.F., Backman, S.J., 2001. An examination of golf travelers’ satisfaction, perceived value, loyalty, and intentions to revisit. Tour. Anal. 6 (3/4), 223-237.

Petrick, J.F., Sirakaya, E., 2003. Segmenting cruisers by loyalty. Ann. Tour. Res. 31 (2), 472475.

Petrick, J.F., 2004a. Are loyal visitors’ desired visitors? Tour. Manage. 25 (4), 463-470.

Petrick, J.F., 2004b. First timers and repeaters’ perceived value. J. Travel Res. 43 (1), 29-38.

Petrick, J.F., 2005a. Reoperationalizing the loyalty framework. Tour. Hosp. Res. 5 (3), 199-212.

Petrick, J.F., 2005b. Segmenting cruise passengers with price sensitivity. Tour. Manage. 26 (5), $753-762$. 
Phillips, R.L., 2005. Pricing and Revenue Optimization. Stanford University Press, California.

Reichheld, F., Teal, T., 1996. The Loyalty Effect. Harvard Business School Press, Boston, MA.

Reinartz, W., Kumar, V., 2002. The mismanagement of customer loyalty. Harv. Bus. Rev. 80 (7), 86-95.

Reisinger, Y., Mavondo, F., 2005. Travel anxiety and intentions to travel internationally: implications of travel risk perception. J. Travel Res. 45, 212-225.

Rodrigue, J.-P., Notteboom, T., 2013. The geography of cruise shipping: itineraries, not destinations. Appl. Geogr. 38, 31-42.

Sampson, H., 2014. Cruise lines trying to get newcomers on board. Miami Herald. March 9, 2014.

Shani, A., Reichel, A., Croes, R., 2012. Evaluation of segment attractiveness by risk-adjusted market potential: first-time vs. repeat visitors. J. Travel Res. 51 (2), 166-177.

Sun, X., Jiao, Y., Tian, P., 2011. Marketing research and revenue optimization for the cruise industry: a concise review. Int. J. Hosp. Manage. 30 (3), 746-755.

Sun, X., Feng, X., Gauri, D.K., 2014. The cruise industry in China: efforts, progress and challenges. Int. J. Hosp. Manage. 42, 71-84.

Tiefenbacher, J.P., Day, F.A., Walton, J.A., 2000. Attributes of repeat visitors to small touristoriented communities. Soc. Sci. J. 37 (2), 299-308.

Toh, R.S., Rivers, M.J., Ling, T.W., 2005. Room occupancies: cruise lines out-do the hotels. Int. J. Hosp. Manage. 24 (1), 121-135.

Wang, D., 2004. Tourist behaviour and repeat visitation to Hong Kong. Tour. Geogr. 6 (1), 99118. 
Wong, J.Y., Yeh, C., 2009. Tourist hesitation in destination decision making. Ann. Tour. Res. 36 (1), 6-23. 
Table 1. Number of Data Records in Each Sample Group.

\begin{tabular}{lll}
\hline Group by history & \multicolumn{1}{c}{$\begin{array}{c}\text { Number of records for } \\
\text { analysis }\end{array}$} & Percentage of the total dataset \\
\hline New cruisers & 89,764 & $9.6 \%$ \\
Two-time cruisers & 33,131 & $100 \%$ \\
Three-time cruisers & 3248 & $100 \%$ \\
Four-time cruisers & 573 & $100 \%$ \\
Five-time cruisers & 179 & $100 \%$ \\
\hline
\end{tabular}


Table 2. Profile of Cruisers Sampled for Analysis.

\begin{tabular}{|c|c|c|c|c|c|}
\hline & $\begin{array}{c}\text { New } \\
\text { Cruisers }\end{array}$ & $\begin{array}{c}\text { Repeat } \\
\text { Cruisers }\end{array}$ & $\begin{array}{l}\text { First-time } \\
\text { Repeaters }\end{array}$ & $\begin{array}{l}\text { Multi-time } \\
\text { Repeaters }\end{array}$ & Overall \\
\hline \multicolumn{6}{|l|}{ Gender } \\
\hline Male & $44.5 \%$ & $47.2 \%$ & $47.0 \%$ & $48.6 \%$ & $45.3 \%$ \\
\hline Female & $54.7 \%$ & $52.4 \%$ & $52.6 \%$ & $51.1 \%$ & $54.1 \%$ \\
\hline Age & 42.11 & 45.96 & 48.99 & 54.27 & 44.29 \\
\hline Location/distance & 750.63 & 546.79 & 563.68 & 406.97 & 690.98 \\
\hline \multicolumn{6}{|l|}{ Embarking port } \\
\hline Port 1 & $3.3 \%$ & $7.2 \%$ & $7.2 \%$ & $6.8 \%$ & $4.4 \%$ \\
\hline Port 2 & $25.1 \%$ & $27.9 \%$ & $28.0 \%$ & $27.4 \%$ & $26.0 \%$ \\
\hline Port 3 & $52.4 \%$ & $49.5 \%$ & $49.3 \%$ & $51.5 \%$ & $51.6 \%$ \\
\hline Port 4 & $19.1 \%$ & $15.4 \%$ & $15.5 \%$ & $14.3 \%$ & $18.0 \%$ \\
\hline \multicolumn{6}{|l|}{ Cruise Itinerary } \\
\hline Market 1 & $26.6 \%$ & $20.5 \%$ & $20.5 \%$ & $20.8 \%$ & $24.8 \%$ \\
\hline Market 2 & $4.0 \%$ & $0.9 \%$ & $1.0 \%$ & $0.4 \%$ & $3.1 \%$ \\
\hline Market 3 & $23.6 \%$ & $18.6 \%$ & $18.7 \%$ & $17.4 \%$ & $22.1 \%$ \\
\hline Market 4 & $7.1 \%$ & $5.2 \%$ & $5.4 \%$ & $4.2 \%$ & $6.5 \%$ \\
\hline Market 5 & $38.5 \%$ & $54.1 \%$ & $53.9 \%$ & $55.9 \%$ & $43.0 \%$ \\
\hline Market 6 & $0.3 \%$ & $0.6 \%$ & $0.5 \%$ & $1.4 \%$ & $0.4 \%$ \\
\hline Cruise Duration & 5.46 & 5.94 & 5.93 & 5.97 & 5.60 \\
\hline Reservation time & 12.57 & 13.18 & 13.30 & 12.19 & 12.75 \\
\hline \multicolumn{6}{|l|}{ Cabin type } \\
\hline Ocean View & $40.8 \%$ & $33.5 \%$ & $34.1 \%$ & $28.9 \%$ & $38.7 \%$ \\
\hline Interior & $40.2 \%$ & $38.8 \%$ & $38.5 \%$ & $40.1 \%$ & $39.8 \%$ \\
\hline Balcony & $14.4 \%$ & $23.2 \%$ & $23.0 \%$ & $25.9 \%$ & $17.0 \%$ \\
\hline Suite & $4.5 \%$ & $4.5 \%$ & $4.5 \%$ & $5.1 \%$ & $4.5 \%$ \\
\hline Price & 451.77 & 486.03 & 487.20 & 476.38 & 461.80 \\
\hline
\end{tabular}

Notes: Location/distance is the distance in miles from the capital city of the cruiser's

home state to their chosen embarkation port; Cruise itinerary represent collapsed sets of similar sailing destinations and durations that are masked here to maintain confidentiality of the data; Cruise duration is the length of the cruise in days; Reservation time is the number of weeks before the sailing date that the cruise was booked; Cabin type is the type of cabin in the ship. 
Table 3a. Results of testing between the two groups.

\begin{tabular}{|c|c|c|c|c|}
\hline & New Cruisers & Repeaters & $\chi^{2}$ or $t$ value & Sig. (p-value) \\
\hline Age & 42.11 & 45.96 & $t=-77.11$ & 0.000 \\
\hline Location/distance & 750.63 & 546.79 & $t=60.90$ & 0.000 \\
\hline Duration & 5.46 & 5.94 & $t=-42.73$ & 0.000 \\
\hline Reservation time & 12.57 & 13.18 & $t=-8.68$ & 0.000 \\
\hline Cabin type & & & $\chi_{(3)}^{2}=1401.98$ & 0.000 \\
\hline Ocean View & $40.8 \%$ & $33.5 \%$ & & \\
\hline Interior & $40.2 \%$ & $38.8 \%$ & & \\
\hline Balcony & $14.4 \%$ & $23.2 \%$ & & \\
\hline Suite & $4.5 \%$ & $4.5 \%$ & & \\
\hline Price & 451.77 & 486.03 & $t=-19.86$ & 0.000 \\
\hline
\end{tabular}

Table 3b. Results of testing between the three groups.

\begin{tabular}{|c|c|c|c|c|c|}
\hline & $\begin{array}{c}\text { New } \\
\text { Cruisers }\end{array}$ & $\begin{array}{l}\text { First-time } \\
\text { Repeaters }\end{array}$ & $\begin{array}{c}\text { Multi-time } \\
\text { Repeaters }\end{array}$ & $\chi^{2}$ or $F$ value & $\begin{array}{c}\text { Sig. (p- } \\
\text { value) }\end{array}$ \\
\hline Age & 42.11 & 48.99 & 54.27 & $F=3210.13$ & 0.000 \\
\hline Location/distance & 750.63 & 563.68 & 406.97 & $F=2008.33$ & 0.000 \\
\hline Duration & 5.46 & 5.93 & 5.97 & $F=960.92$ & 0.000 \\
\hline Reservation time & 12.57 & 13.30 & 12.19 & $F=56.21$ & 0.000 \\
\hline Cabin type & & & & $\chi_{(3)}^{2}=1438.52$ & 0.000 \\
\hline Ocean View & $40.8 \%$ & $34.1 \%$ & $28.9 \%$ & & \\
\hline Interior & $40.2 \%$ & $38.5 \%$ & $40.1 \%$ & & \\
\hline Balcony & $14.4 \%$ & $23.0 \%$ & $25.9 \%$ & & \\
\hline Suite & $4.5 \%$ & $4.5 \%$ & $5.1 \%$ & & \\
\hline Price & 451.77 & 487.20 & 476.38 & $F=210.27$ & 0.000 \\
\hline
\end{tabular}


Table 4. Tests of Between-Subjects Effects in terms of group and cabin type.

\begin{tabular}{|c|c|c|c|c|c|}
\hline \multicolumn{6}{|l|}{ Dependent Variable: Price } \\
\hline Source & Type III Sum of Squares & df & Mean Square & $\mathbf{F}$ & Sig. \\
\hline Corrected model & 4.09E9 & 11 & $3.72 \mathrm{E} 8$ & 8798.87 & 0.00 \\
\hline Intercept & 1.30E10 & 1 & 1.30E10 & 306163.00 & 0.00 \\
\hline Cruiser group & 1388634.46 & 1 & 1388634.46 & 32.83 & 0.00 \\
\hline Cabin type & 3.63E9 & 5 & 7.27E8 & 17181.05 & 0.00 \\
\hline Cruiser group * cabin type & 11954767.61 & 5 & 2390953.52 & 56.52 & 0.00 \\
\hline Error & 5.37E9 & 12688 & 42303.70 & & \\
\hline Total & 3.65E10 & 12689 & & & \\
\hline Corrected total & $9.46 \mathrm{E} 9$ & 12689 & & & \\
\hline Adj. $R^{2}=0.43$ & & & & & \\
\hline
\end{tabular}


Table 5. Results of testing differences in price for each cabin type.

\begin{tabular}{|c|c|c|c|c|c|c|c|}
\hline Cabin Types & Percent & Groups & $\mathbf{N}$ & Mean & $\mathbf{t}$ & Sig. & Difference \\
\hline \multirow{2}{*}{ Ocean View } & \multirow{2}{*}{$38.7 \%$} & New & 33235 & 413.36 & \multirow{2}{*}{-10.40} & \multirow{2}{*}{0.00} & \multirow{2}{*}{ Yes } \\
\hline & & Repeat & 11240 & 436.02 & & & \\
\hline \multirow{2}{*}{ Interior } & \multirow{2}{*}{$39.8 \%$} & New & 32749 & 354.38 & \multirow{2}{*}{-1.41} & \multirow{2}{*}{0.16} & \multirow{2}{*}{ No } \\
\hline & & Repeat & 13005 & 356.89 & & & \\
\hline \multirow{2}{*}{ Balcony } & \multirow{2}{*}{$17.0 \%$} & New & 11763 & 788.81 & \multirow{2}{*}{-10.40} & \multirow{2}{*}{0.00} & \multirow{2}{*}{ Yes } \\
\hline & & & 7768 & 763.60 & & & \\
\hline \multirow[b]{2}{*}{ Suite } & \multirow{2}{*}{$4.5 \%$} & New & 3687 & 919.35 & \multirow{2}{*}{-5.84} & \multirow[b]{2}{*}{0.00} & \multirow{2}{*}{ Yes } \\
\hline & & Repeat & 1525 & 991.52 & & & \\
\hline
\end{tabular}


Table 6. Results of testing differences in price between groups for each cabin type.

\begin{tabular}{llllll}
\hline \multicolumn{1}{l}{ Cabin types } & \multicolumn{1}{c}{ Ocean View } & \multicolumn{1}{c}{ Interior } & \multicolumn{1}{c}{ Balcony } & \multicolumn{1}{c}{ Suite } \\
\hline ANOVA & $\mathrm{F}=56.91$ & $\mathrm{~F}=4.63$ & $\mathrm{~F}=29.11$ & $\mathrm{~F}=18.33$ \\
& $\mathrm{P}=0.00$ & $\mathrm{p}=0.01$ & $\mathrm{p}=0.00$ & $\mathrm{p}=0.00$ \\
\multicolumn{2}{l}{ Post hoc analysis } & Sig. & Sig. & Sig. & Sig. \\
New & Two-time & $0.00^{* *}$ & $0.09^{*}$ & $0.00^{* *}$ & $0.00^{* *}$ \\
New & Multi-time & $0.03^{* *}$ & 0.12 & $0.00^{* *}$ & $0.10^{*}$ \\
Two-time & Multi-time & $0.45^{*}$ & $0.02^{* *}$ & $0.02^{* *}$ & 0.92 \\
\hline
\end{tabular}

* The mean difference is significant at the 0.10 level.

** The mean difference is significant at the 0.05 level. 
Table 7. Results of the current study.

\begin{tabular}{|c|c|c|}
\hline Variables & Previous findings & Current study \\
\hline \multirow[t]{2}{*}{$\begin{array}{l}\text { - Reservation } \\
\text { Timing }\end{array}$} & Cruise tourism: None. & $\begin{array}{l}\text { New cruisers reserve cruises } \\
\text { less in advance of departure than } \\
\text { repeaters, though multi-time } \\
\text { repeaters book their cruises } \\
\text { closest in to the trip departure. }\end{array}$ \\
\hline & 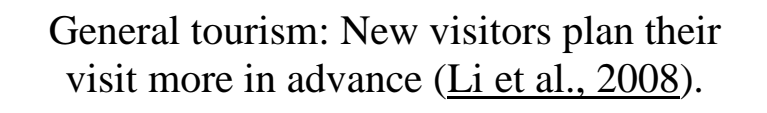 & \\
\hline \multirow[t]{2}{*}{$\begin{array}{l}\text { Duration } \\
\text { (Length of stay) }\end{array}$} & $\begin{array}{l}\text { Cruise tourism: People generally allocate } \\
\text { less time for their first cruise than } \\
\text { subsequent cruises (CLIA, 2011). }\end{array}$ & $\begin{array}{l}\text { - New cruisers purchase shorter } \\
\text { cruises than repeat cruisers }\end{array}$ \\
\hline & $\begin{array}{l}\text { General tourism: New visitors generally } \\
\text { have shorter stays than repeaters } \\
\text { (Oppermann, 1997, 1998; Tiefenbacher et } \\
\text { al., 2000; Wang, 2004; Lau and McKercher, } \\
\text { 2004; c.f. Li et al., 2008; Shani et al., 2012). }\end{array}$ & \\
\hline $\begin{array}{l}\text { Location } \\
\text { (Distance of } \\
\text { travel) }\end{array}$ & Cruise tourism: None. & $\begin{array}{l}\text { New cruisers travel further to } \\
\text { embarking ports than repeaters. }\end{array}$ \\
\hline
\end{tabular}

General tourism: New visitors tend to travel greater distance than repeaters

(Tiefenbacher et al., 2000; Li et al., 2008).

Cruise
Spending Fare
Price

Cruise tourism: New cruisers and repeaters do not differ in terms of cruise spending (Petrick, 2004a).

- New cruisers spend less than repeaters. Cruisers who repeat for the first time spend the most.

General tourism: New tourists tend to spend more money than repeaters (Oppermann, 1997).

Cruise Spending: Cabin type selection

Suites

\section{Balcony}

Cruise Tourism: None.
- In general, repeat cruisers are more likely to choose better cabins than new cruisers.

- Multi-time repeat cruisers are more likely to choose suites than first-time repeaters or new cruisers.

Repeat cruisers are more likely to stay in balcony cabins than new cruisers. 


\begin{tabular}{ll}
\hline Variables & Previous findings \\
\hline Ocean View & \\
Interior & \\
& \\
a Cruise & Cruise Tourism: None. \\
Spending: Price & \\
* Cabin Type & \\
Suite &
\end{tabular}

Balcony

Ocean View

Interior

\section{Current study}

- New cruisers are more likely to stay in ocean-view cabins than repeaters.

- New cruisers are more likely to stay in interior cabins than repeaters.

- New cruisers spend less than repeaters for suites

- New cruisers tend to spend more than repeaters for balcony cabins.

- New cruisers tend to spend less than repeaters for oceanview cabins.

- Two-time cruisers spend more for interior cabins than new cruisers and multiple-repeaters. 


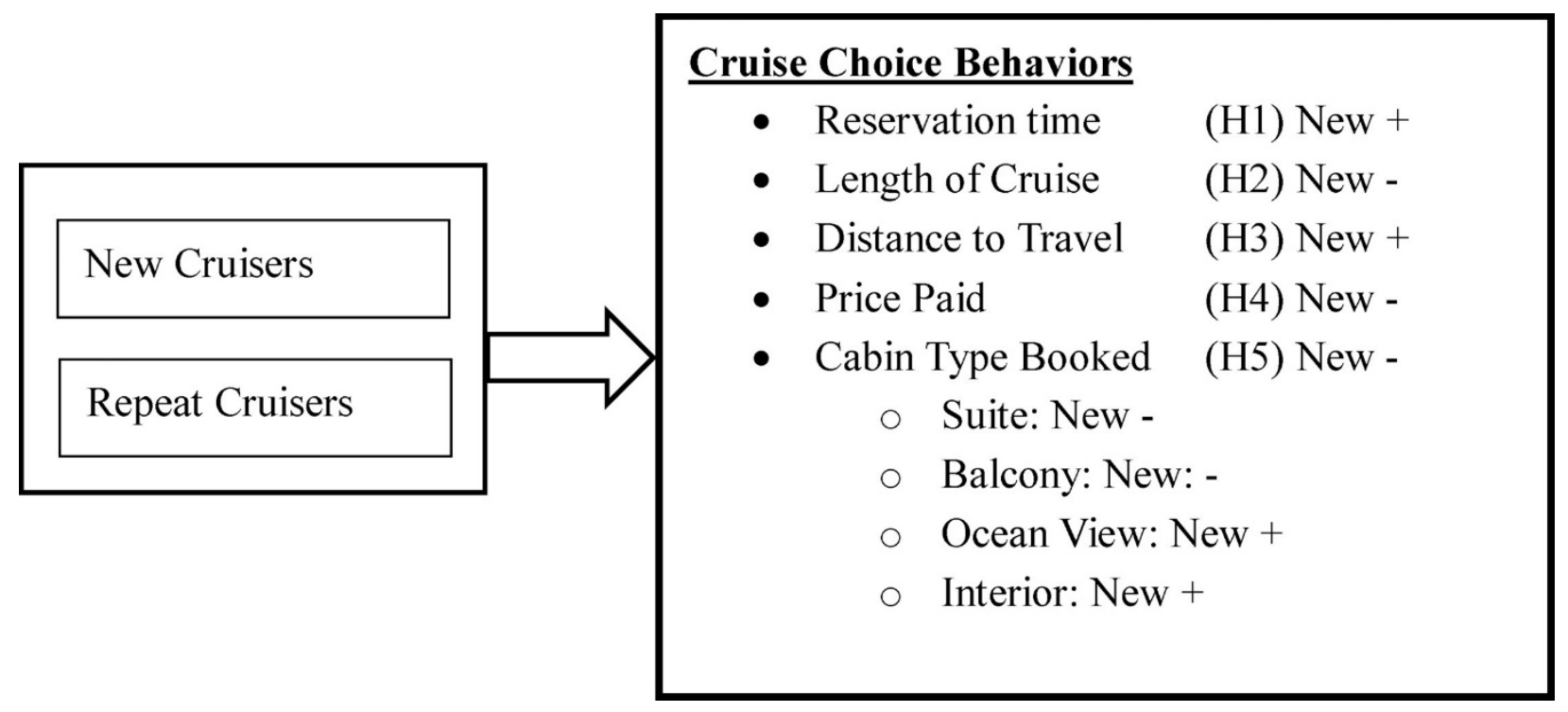

Figure 1. Empirical Framework. 


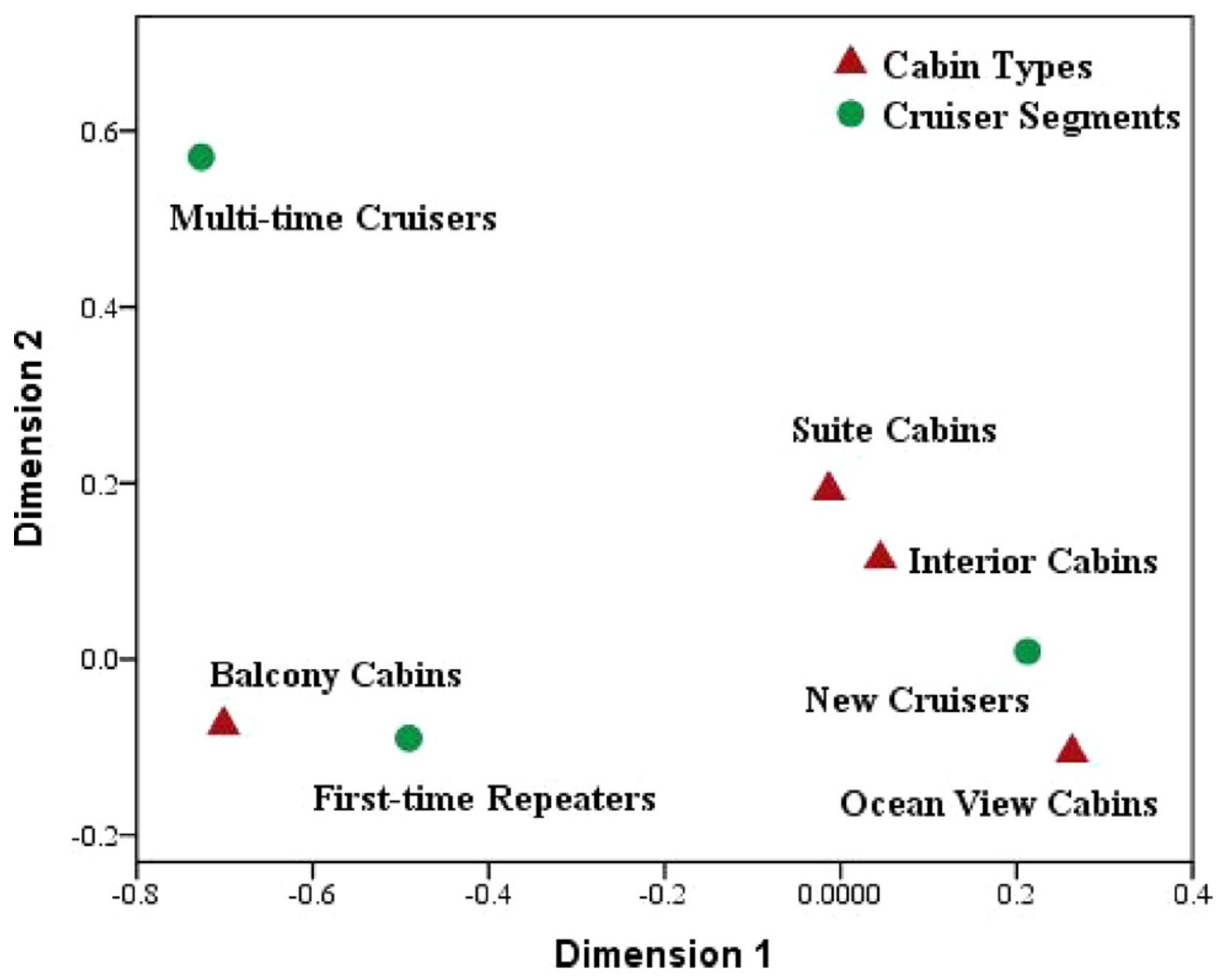

Figure 2. Correspondence analysis for cabin type selection.

Note: Like the extraction of principal components in Factor Analysis, correspondence analysis transforms the data into an equivalent space by vividly representing the interrelationships of categories of row and column variables on a two-dimension map, where the first dimension (Dimension 1) captures the largest amount of variability (inertia) in the data points, followed by the second dimension (Dimension 2). 


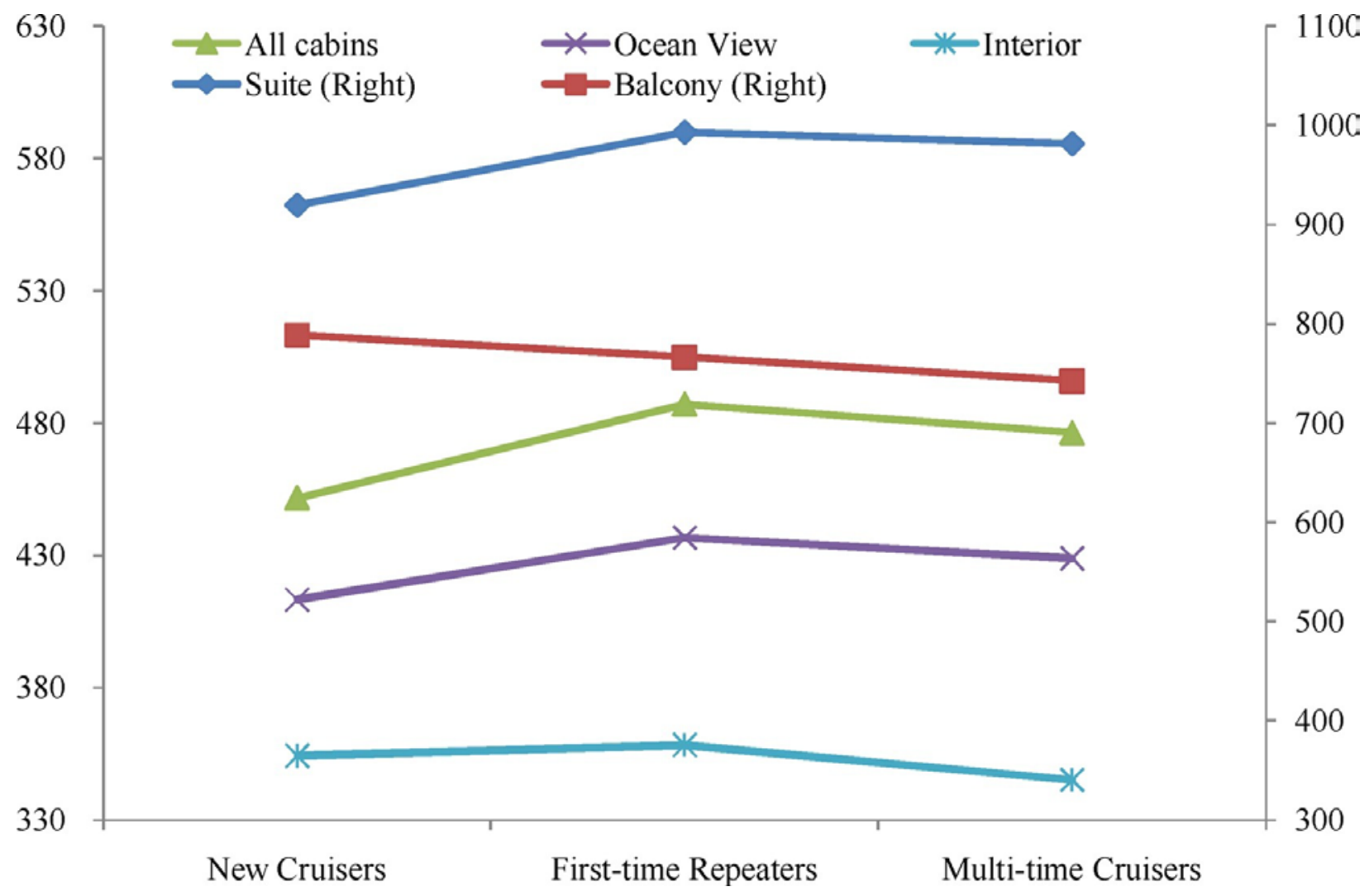

Figure 3. Relationship of cabin prices and cruiser groups. 


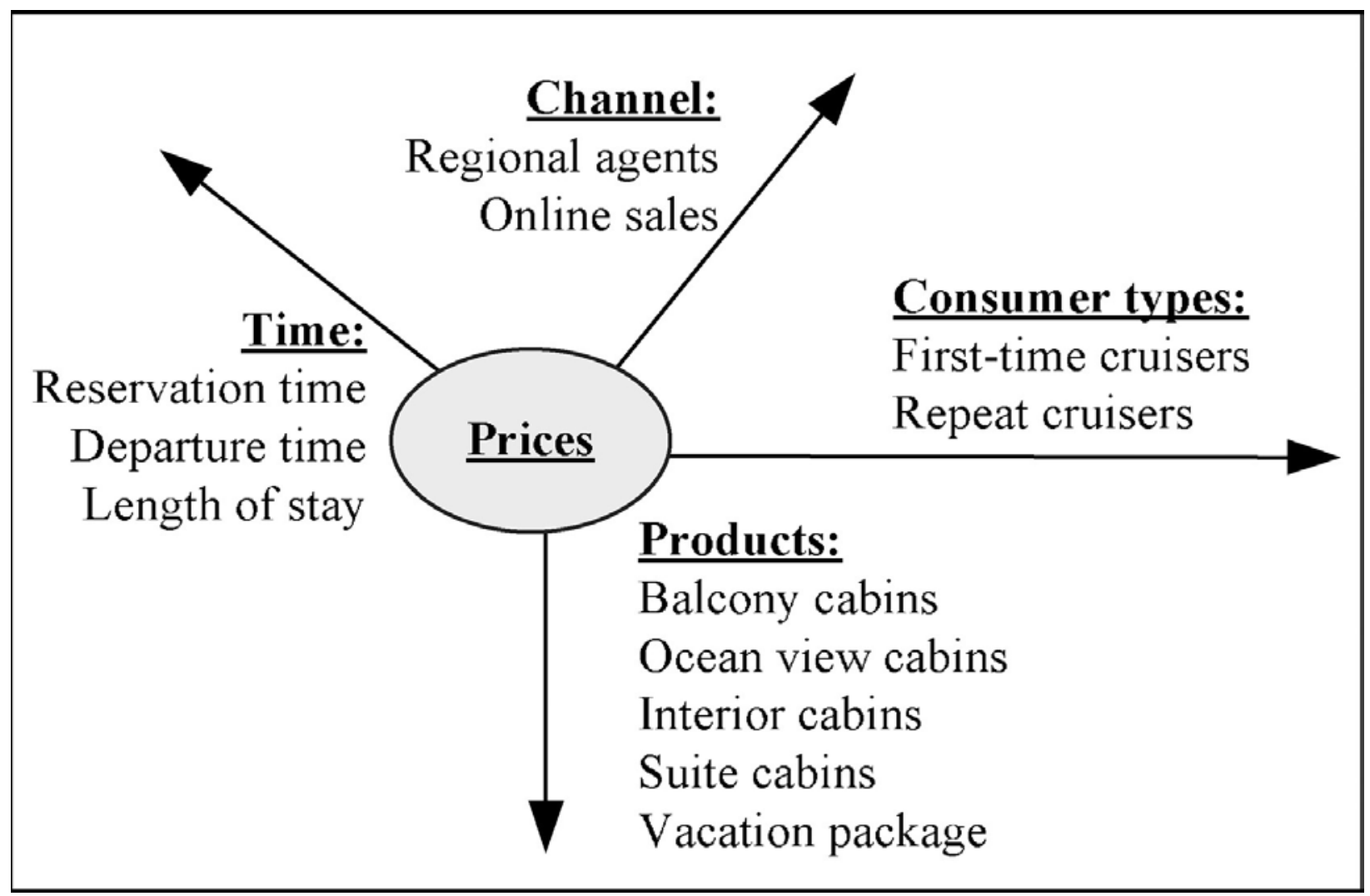

Figure 4. Revenue management problem based on past experience of cruisers. 